\title{
Teacher sense of efficacy among Malaysian agriculture student teachers
}

\begin{abstract}
This exploratory descriptive study sought to investigate teachers' efficacy beliefs among agriculture science student teachers in Universiti Putra Malaysia (UPM). Specifically, the study explored student teachers' efficacy beliefs in terms of student engagement, instructional strategies, and classroom management. The study also attempted to explain the relationships between student teachers' backgrounds variables and teachers' sense of efficacy beliefs. The study showed that general teacher efficacy beliefs among UPM agriculture science student teachers was high (Mean=4.15, SD. =.33). Male student teachers were found to have a significantly higher general teacher efficacy beliefs than female students teachers $(\mathrm{t}(79)=$ 2.20, $\mathrm{p}=.031)$. Experienced student teachers were more efficacious than student teachers who have no experience at all $(\mathrm{t}(79)=3.072, \mathrm{p}=.003)$. Age correlated significantly with general teacher efficacy belief $(\mathrm{r}=.51, \mathrm{p}<.01)$. Significant correlations were also found between CGPA and general teacher efficacy belief $(\mathrm{r}=.31, \mathrm{p}<.01)$
\end{abstract}

Keyword: Teacher Sense of Efficacy, Agriculture Student Teachers, Teaching Confidence 